\title{
Does Online Anonymity Boost Illegal Market Trading?
}

DOI:

$10.1177 / 0163443719842075$

\section{Document Version}

Accepted author manuscript

Link to publication record in Manchester Research Explorer

\section{Citation for published version (APA):}

Aldridge, J. (2019). Does Online Anonymity Boost Illegal Market Trading? Media, Culture and Society. https://doi.org/10.1177/0163443719842075

\section{Published in:}

Media, Culture and Society

\section{Citing this paper}

Please note that where the full-text provided on Manchester Research Explorer is the Author Accepted Manuscript or Proof version this may differ from the final Published version. If citing, it is advised that you check and use the publisher's definitive version.

\section{General rights}

Copyright and moral rights for the publications made accessible in the Research Explorer are retained by the authors and/or other copyright owners and it is a condition of accessing publications that users recognise and abide by the legal requirements associated with these rights.

\section{Takedown policy}

If you believe that this document breaches copyright please refer to the University of Manchester's Takedown Procedures [http://man.ac.uk/04Y6Bo] or contact uml.scholarlycommunications@manchester.ac.uk providing relevant details, so we can investigate your claim.

\section{OPEN ACCESS}


Media, Culture \& Society

(C) The Author(s) 2019

Article reuse guidelines:

sagepub.co.uk/journalsPermissions.nav

DOI: $10.1177 / 0163443719842075$

journals.sagepub.com/home/mcs

\title{
Does Online Anonymity Boost Illegal Market Trading?
}

\author{
Judith Aldridge, University of Manchester, UK
}

\begin{abstract}
Anonymity allows the online trade in illegal products and services on cryptomarkets to flourish in spite of being enacted in a public location. Bolstered by the extensive media coverage of the cryptomarket trade in drugs, fraud and weapons, these platforms may function as a kind of criminal 'gateway', and in so doing facilitate - or indeed amplify criminality. I argue, however, that researchers must establish - not assume - that the criminality facilitated by online anonymity will exclusively and uniformly produce more harmful outcomes. I consider here two possibilities in connection to the cryptomarket trade in illegal drugs: reduced drug market violence and reduced drug harms to users. Whether these potential 'benefits' are viewed as valuable will vary and depend substantially on the perspective and interests of the observer, including drug sellers, drug buyers, law enforcement officials, and academic researchers.
\end{abstract}

\section{Keywords}

Online anonymity, cryptomarkets, Darknet, illegal drugs, harm reduction, drug markets, violence 
The internet has facilitated deviant and criminal activity throughout its history in relation to illegal drug selling, pornography, fraud and terrorism - to name a few. And - as internet technologies grow to sustain more and more of our personal and working lives - so too will the illegal opportunities these developments make possible.

It has, however, been the comparatively recent development of 'cryptomarkets' in which we have witnessed what has proved a step-change in criminal innovation facilitated by the internet (Aldridge and Décary-Hétu, 2014). Cryptomarkets mimic legal online platforms like eBay or Amazon in bringing together multiple vendors hosted by marketplaces that provide third-party services. The step-change is anonymity. Marketplaces are accessed via anonymizing software like Tor, and payments are made using cryptocurrencies like Bitcoin; both function to obscure the link between marketplace activity and real-world identities. Of course, a degree of anonymity is essential for any successful illegal transaction - whether online or offline. A law enforcement agency so-tasked may be aware of illegal activity - like drug selling - on its patch but will remain impotent until an evidential trail can be established between that activity and individuals with verifiable identities. Because cryptomarket platforms provide this anonymity, they may boost illegal trading.

Anonymity, moreover, allows the trade in illegal products and services on cryptomarkets to flourish in spite of being enacted in a public location; indeed, in plain sight of law enforcement. Their public location makes the cryptomarket trade accessible to anyone so-inclined and with an internet connection to observe and do so legally. Bolstered by the extensive media coverage of the cryptomarket trade in drugs, fraud and weapons, these platforms may simultaneously function as a kind of criminal 'gateway'. Researchers have documented increased marketplace activity even after extensive media coverage of law enforcement operations targeting cryptomarkets and high-profile court cases. It is not just those already involved in illegal market trading who may weigh up the relative risks and benefits of moving their enterprises online; so too might the uninitiated, after accessing the cryptomarketplace, recognize illicit earning opportunities and even be tutored via discussion in marketplace forums in reducing the risk of arrest (see Aldridge and Askew, 2017). For example, a cryptomarket buyer while browsing a marketplace for a small quantity of cannabis for personal use may realise the potential for profitable resale of bulk purchases available at discounted prices. Cryptomarkets functioning as 'gateways' may therefore recruit individuals and thereby expand numbers of illegal market participants. 


\section{Considering the benefits of illegal trading on cryptomarkets}

It is entirely possible, therefore, that the anonymity on which cryptomarkets rely may boost illegal market trading. But is this inevitably a 'bad' development? I offer here two potential benefits in connection to the sale of illegal drugs on cryptomarkets.

\section{Reducing harm to drug users}

One source of potential harm for people who take drugs derives from the considerable variation in the content and purity of substances sold by drug dealers in unregulated illegal markets. On first consideration, one might imagine that the shield of online anonymity could function to make cryptomarket drug vendors even less accountable to their customers, and therefore more likely to sell adulterated products. Cryptomarkets off-set this problem via mechanisms built-in to marketplace platforms designed to establish accountability in the absence of offline trust developed face-to-face. For example, cryptomarkets incentivize customer satisfaction via aggregated sales feedback metrics that guide new customers to reliable vendors and products generated by reviews from previous buyers. 'Third party' services provided by marketplaces similarly incentivize customer satisfaction: marketplaces first hold customer payment in 'escrow'; this is only later released to a vendor when the satisfied customer finalizes the transaction. It is possible that cryptomarket vendor accountability may produce a net-benefit effect on product quality. A recent review of scientific evidence suggests that cryptomarket vendors may be more likely than their offline counterparts to sell higher purity products in which the substance type matches the 'as advertised' description (Aldridge et al., 2017).

\section{Reducing opportunities for violence in illegal markets}

Although research suggests that the violence associated to illegal markets is the exception rather than the rule, participants must nevertheless resolve disputes without the benefit of legitimate state agencies, making violence more likely than in legal markets. Anonymity combined with the virtual location of cryptomarkets, however, reduces opportunities for violence, and third-party marketplace services tend to favour peaceable approaches to conflict resolution (Morselli et al., 2017). Martin (2017) suggests cryptomarkets may 'gentrify' drug markets by altering distribution networks to exclude violent organized crime groups. As noted above, cryptomarkets tend to favor the trade of drugs like MDMA and cannabis that are associated with less drug market violence than 
others, like heroin and cocaine. If cryptomarkets continue to grow, one possibility is that drug market violence may be reduced via shifts in drug demand away from substances with relatively high levels of violence associated to their production and trafficking, instead favoring the more 'ethically produced' drugs that predominate selling on cryptomarkets.

\section{Informal nodal governance}

When markets are illegal, they function in spaces where formal/state governance is limited; this makes illegal buying and selling prone to instability, uncertainty and risk for all parties. Cryptomarkets - enabled by online anonymity - can be understood to function as sites of informal 'nodal governance' (Martin, 2014). The concept of nodal governance is valuable in helping us understand the complex ways that actors, actions and norms produce regulatory outcomes not always intended or part of 'top down' planning. Cryptomarket participants effectively operate in a self-regulating ecosystem designed to facilitate illegal trading: to make it more stable, more certain, less risky. More than this, the nodal governance frame requires us to take a wide-angle view in understanding how regulation actually comes about, considering the range of possible actors, including formal state actors, but also criminal actors, scientists, policy makers, and more. But as Burris, Drahos, and Shearing (2005 p. 34)) demonstrate, "nodal governance is neither necessarily democratic nor a method that secures more goods than bads". Does the cryptomarket's self-regulation result in more 'goods' or more 'bads'? The answer may depend on perspective.

\section{Discussion: a question of perspective}

My aim has been to stimulate critical thinking about the illegal market innovations that online anonymity has enabled. I have suggested that cryptomarkets may have benefits in connection to their trade in illegal drugs: reduced harms for people who take drugs, and reduced drug market violence. These suggestions are admittedly speculative; reasoned conjecture derived from an as-yet fairly limited evidence base. I do not deny that drug cryptomarkets may also exacerbate drug harms, for example by increasing the population prevalence of use across a wider range of drugs, as I have argued elsewhere (Aldridge et al., 2017), and do not claim that benefits outweigh harms. Some readers may view even the suggestion that criminal innovations can have benefits as controversial; perhaps even counter-intuitive. How can a marketplace that facilitates the sales of illegal drugs actually 
reduce harms to people who use drugs? Or reduce drug market violence? And yet, as I hope I have shown, these benefits are plausible, and to an extent also evidenced. If we do not allow for the possibility that criminal innovations may carry benefits, law enforcement and other policy responses may produce unanticipated and unwanted consequences.

The recent Europol and EMCDDA (2017) report 'Drugs and the Darknet: Perspectives for enforcement, research and policy' is a case in point. It offers only recommendations for more effective policing designed to disrupt online markets but does not consider their unanticipated consequences. Its authors do not consider, for example, the potentially harmful consequences of diverting the drug trade back to offline markets where associated drug harms and violence may be greater. 'Success' gauged only by successful marketplace disruption and arrests may be short-sighted and discourage policy makers from attending to complexities more visible when taking a broader perspective.

Of course, whether the potential for cryptomarkets to reduce drug harms and drug market violence is viewed as valuable depends on the perspective of the observer. If cryptomarkets indeed facilitate seller accountability and drug buyers can therefore be more certain of the content and purity of their purchases, this is likely to be deemed valuable by drug consumers. Similarly, both drug buyers and vendors are likely to value marketplaces that reduce the likelihood of encountering transactional violence. In contrast, those who view the war on drugs as winnable and all illegal drug use as exclusively harm-producing may resist casting any so-called benefits to drug users and sellers as a desirable outcome. On the contrary, any developments that benefit drug users and sellers may be interpreted as evidence of the greater threat cryptomarkets pose by enabling more effective - less risky - buying and selling of dangerous illegal substances that we should be seeking to stop, not facilitate.

Advocates of drug 'harm reduction' strategies, by comparison, may identify any benefits of the cryptomarket drug trade as valuable. This perception may be even more likely for those who attribute much drug-related harm to drug prohibition itself - harms they believe that effective state-regulation would be better placed to reduce. The interests of drug policy reform advocates may lead them to value any benefits cryptomarkets bring where these provide further evidence to bolster the case for reform, as illustrated by Power (2017) in his recommendation to make cannabis available legally in online markets using the tried-andtested cryptomarket model. In sum, whether the potential benefits of illegal drug trading facilitated by online anonymity are deemed viable - or indeed valuable at all - depends on the political and value orientations of the observer. Preferred approaches for responding to these innovations, moreover, cannot be understood without simultaneously identifying how 
these favor particular group interests. Law enforcement, for example, face the need to recruit new staff or up-skill existing staff with expertise in the digital realm relevant to anonymityfacilitated cybercrime; success in doing so builds capacity and professionalization within an ever-growing sector whose interests will then be even more closely aligned with strategies that maintain and grow these capacities.

Online anonymity enables illegal market activity to be enacted in a public location. As a result, researchers have gained unprecedented insight into illegal markets using 'digital trace' methods (Décary-Hétu and Aldridge, 2015); insights previously limited by data derived from more partial law enforcement intelligence and disclosures to researchers by small numbers of (mostly arrested) individuals (Barratt and Aldridge, 2016). The 'big data' collected using automated methods from cryptomarkets captures exceptionally detailed information on price, sales, product types and product flows unavailable in connection to illegal markets operating offline. The size of datasets now being generated is vast: many thousands of vendors, hundreds of thousands of buyers, and many millions of illicit transactions. These data are now enabling researchers to track trends precisely over time, to ascertain the effects of law enforcement activities, and to provide unrivalled drug demand and supply monitoring information (Martin et al. 2018).

Using similar data collection methods, law enforcement actors have access to unprecedented intelligence connected to their operations. Moreover, the anonymity that protects online buyers and sellers of illegal products, equally, benefits law enforcement actors who can then more easily infiltrate marketplaces for undercover operations that provide unique operational intelligence. In spite of some law enforcement 'successes' informed by rich operational intelligence data and resulting in disruption, site closures, and many arrests, these marketplaces remain resilient. Some have argued that the abundance of intelligence available on anonymous online markets - to those on both sides of the law - serves primarily to speed the pace of innovation (Aldridge and Askew, 2017), with marketplace platforms developing more sophisticated strategies to evade detection in response to law enforcement activities, and in turn prompt law enforcement to devise ever more sophisticated tactics.

My message is this: researchers must establish - not assume - that the criminality facilitated by online anonymity will exclusively and uniformly produce more harmful outcomes. Doing so requires scholars and policy makers to articulate and then question their assumptions, and to design research that enables them to test a wide range of hypotheses, including some that may challenge the status quo or risk producing results unpalatable to some. We must consider seriously the benefits alongside the harms of criminal innovations. 
If we do not, we risk designing research informed by partial, short-sighted or politicallydriven understanding that produces limited or even misleading results and ineffective policy responses.

\section{Funding}

The author received no financial support for the research, authorship, and/or publication of this article.

\section{References}

Aldridge J and Askew R. (2017) Delivery dilemmas: How drug cryptomarket users identify and seek to reduce their risk of detection by law enforcement. International Journal of Drug Policy 41: 101-109.

Aldridge J and Décary-Hétu D. (2014) Not an 'eBay for Drugs': The Cryptomarket "Silk Road" as a Paradigm Shifting Criminal Innovation. Available at SSRN: http://ssrn.com/abstract=2436643.

Aldridge J, Stevens A and Barratt M. (2017) Will growth in cryptomarket drug buying increase the harms of illicit drugs? Addiction.

Barratt MJ and Aldridge J. (2016) Everything you always wanted to know about drug cryptomarkets* (*but were afraid to ask). International Journal of Drug Policy 35: 1-6.

Burris, S., P. Drahos and C. Shearing (2005). "Nodal governance." Austl. J. Leg. Phil. 30: 30.

Décary-Hétu D and Aldridge J. (2015) Sifting through the net: Monitoring of online offenders by researchers. European Review of Organized Crime 2: 122-141. 
Europol and EMCDDA. (2017) Drugs and the Darknet. Perspectives for enforcement, research and policy. Luxembourg.

Martin J. (2017) Cryptomarkets, systemic violence and the 'gentrification hypothesis'. Addiction.

Martin, J., J. Cunliffe, D. Décary-Hétu and J. Aldridge (2018). "Effect of restricting the legal supply of prescription opioids on buying through online illicit marketplaces: interrupted time series analysis." BMJ 361.

Martin, J. (2014). Drugs on the dark net: how cryptomarkets are transforming the global trade in illicit drugs, Palgrave Macmillan.

Morselli C, Décary-Hétu D, Paquet-Clouston M, et al. (2017) Conflict Management in Illicit Drug Cryptomarkets. International Criminal Justice Review: 1057567717709498.

Power M. (2017) The Green Screen. London: Volte Face. 